ARTICLE

Received 24 Feb 2015 | Accepted 25 Nov 2015 | Published 21 Dec 2015

DOI: $10.1038 /$ ncomms10278

OPEN

\title{
Rational engineering of a mesohalophilic carbonic anhydrase to an extreme halotolerant biocatalyst
}

\author{
Andrew C. Warden ${ }^{1,2}$, Michelle Williams ${ }^{1,2}$, Thomas S. Peat ${ }^{3}$, Shane A. Seabrook ${ }^{3}$, Janet Newman ${ }^{3}$,
} Greg Dojchinov ${ }^{1,2} \&$ Victoria S. Haritos ${ }^{1,4}$

Enzymes expressed by highly salt-tolerant organisms show many modifications compared with salt-affected counterparts including biased amino acid and lower $\alpha$-helix content, lower solvent accessibility and negative surface charge. Here, we show that halotolerance can be generated in an enzyme solely by modifying surface residues. Rational design of carbonic anhydrase II is undertaken in three stages replacing 18 residues in total, crystal structures confirm changes are confined to surface residues. Catalytic activities and thermal unfolding temperatures of the designed enzymes increase at high salt concentrations demonstrating their shift to halotolerance, whereas the opposite response is found in the wild-type enzyme. Molecular dynamics calculations reveal a key role for sodium ions in increasing halotolerant enzyme stability largely through interactions with the highly ordered first $\mathrm{Na}^{+}$hydration shell. For the first time, an approach to generate extreme halotolerance, a trait with broad application in industrial biocatalysis, in a wild-type enzyme is demonstrated.

\footnotetext{
${ }^{1}$ Energy Flagship, Commonwealth Scientific and Industrial Research Organisation (CSIRO), GPO Box 1700, Canberra, Australian Capital Territory 2601, Australia. ${ }^{2}$ Land and Water Flagship, Commonwealth Scientific and Industrial Research Organisation (CSIRO), GPO Box 1700, Canberra, Australian Capital Territory 2601, Australia. ${ }^{3}$ Biomedical Manufacturing Program, Commonwealth Scientific and Industrial Research Organisation (CSIRO), 343 Royal Parade, Parkville, Victoria 3052, Australia. ${ }^{4}$ Department of Chemical Engineering, Monash University, Clayton, Victoria 3168, Australia. Correspondence and requests for materials should be addressed to A.C.W. (email: andrew.warden@csiro.au).
} 
$\mathrm{F}$ or many enzymes, an optimal operating environment is characterized by moderate temperature, $\mathrm{pH}$ and salinity range and moving outside of these conditions can lead to rapid denaturation of the protein. In particular, hypersaline conditions can cause aggregation of mesohalophilic enzymes, that is, salt-sensitive, due to an increase in the hydrophobic effect and structural collapse as the high concentration of ions interferes with electrostatic interactions between amino acid residues ${ }^{1}$. There are, however, halophilic enzymes that have been isolated from organisms living in high-salt environments, such as the Dead $\mathrm{Sea}^{2}$, which are stable and perform optimally in these conditions.

Compared with their non-halophile counterparts, halophilic enzymes typically have significantly higher densities of negative charge on their surfaces and reduced levels of lysine and cysteine residues but higher amounts of random coil structure at the expense of $\alpha$-helix, higher content of aspartate and small hydrophobic residues ${ }^{3-6}$. The overall reduction in size of hydrophobic residues in halophilic proteins is thought to be a compensation for an increase in the hydrophobic effect brought about by the increase in the dielectric character of high salt concentrations. Conversely, enzymes from halophilic organisms that show adaptations to high salt conditions do not easily express and fold in typical recombinant systems and are highly unstable in low-salt conditions ${ }^{2}$.

Industrial use of biocatalysts spans from fine chemical and polymer manufacturing ${ }^{7}$, via intermediates and has broadened into energy with biofuels ${ }^{8}, \mathrm{CO}_{2}$ capture ${ }^{9}$ and fuel cells ${ }^{10}$ among others $^{11}$. Halophilic enzymes have received growing attention as biocatalysts in hypersaline environments such as brines, ionic liquids (ILs), ionic detergents and where solutes are formed by gases dissolving into aqueous systems ${ }^{12}$. Sourcing of enzymes for use in high-salt conditions has traditionally been through discovery of halophilic enzymes from natural systems, but this approach can meet significant hurdles in being able to achieve, for example, recombinant protein expression, folding and stability or even the desired catalytic activity. An alternative approach to biological discovery is to rationally design halotolerance into an existing biocatalyst that already possesses the desired attributes of catalytic activity, facile heterologous expression, tolerance of inhibitory chemicals or other essential characteristics.

Recent reports of enzyme engineering that focussed specifically on halotolerance include the characterization of the effect of two amino acid changes on the halophilicity of dinucleotide diphosphate kinase ${ }^{13}$, and a more extensive undertaking that examined the structural basis and amino acid content determining salt tolerance of the $1 \mathrm{~A}$ domain of $\mathrm{NAD}^{+}$. dependent DNA ligase from Haloferax volcanii and the IgG-binding domain of Protein L from Streptococcus magmus ${ }^{14}$. However, these approaches have generally started with knowledge of the halotolerant protein and structure and have worked backwards to the non-tolerant protein.

Thus, to better understand the key factors controlling halophilicity in enzymes and to develop a halotolerant biocatalyst for hypersaline conditions, we undertook rational enzyme design by selecting just one of several mechanisms present in halophilic enzymes: increasing the incidence of acidic residues on the enzyme surface. A well-studied carbonic anhydrase II was selected for rational design as it has efficient $\mathrm{CO}_{2}$ hydration activity and could be heterologously expressed in Escherichia coli. Herein, we describe for the first time the successful redesign of a mesohalophile enzyme to an extremely halotolerant orthologue, that is, one that is active at $3 \mathrm{M} \mathrm{NaCl}$ and above, by altering 18 surface residues. The conversion from mesohalophile to extreme halotolerant enzyme is conducted in stages to assess the effects of substitutions on overall protein stability and degree of halotolerance. Furthermore, molecular dynamics calculations suggest that it is both extended binding of cations by acidic residues with complementary chelating partners, and interactions through the highly ordered hydration shells of the cations that are primary mechanisms of halotolerance.

\section{Results}

Crystal structures of mutants 1-4 (M1-M4). Wild-type (WT) and designed M1-M4 carbonic anhydrases were efficiently expressed in E. coli and purified as folded and functional enzymes using standard procedures (Supplementary Fig. 1). With the exception of N62D, all other substitutions in this study have not been previously investigated in carbonic anhydrase II. The most substituted enzyme, M4, had 10 additional Asp and eight extra Glu residues but five fewer Asn, four fewer Gln, three fewer Lys, two fewer Val and one less Gly, Leu, Arg and Thr residues compared with WT (Supplementary Table 1). Crystal structures of WT and engineered enzymes were obtained to confirm the presence of changed residues, that active site residue positioning was unaffected and also to compare the overall structural similarity of the designed proteins with that of WT. Naturally occurring halophilic enzymes are underrepresented in the protein data bank as these enzymes are generally highly soluble in 'salting out' salts used to generate crystals of mesohalophilic enzymes ${ }^{2}$.

Crystal statistics for the WT and designed enzymes are given in Table 1. The structures of the four engineered enzymes superposed almost perfectly with the WT enzyme (maximum root mean square deviation (RMSD) $=0.42 \AA$ for M4) with no significant differences apparent in their secondary structures (Supplementary Fig. 2). Three of the four variants (M1, M3 and M4) included the mutation N62D, which has been previously reported ${ }^{15}$ and been shown to reduce the activity of human CAII attributed to the effect of holding the side chains of the catalytically important His64 in the 'outwards' position, compared with that determined for the 'inward' facing conformation of this residue. The crystal structures of the three N62D containing enzymes (M1, M3 and M4) also showed His64 as the outwards rotamer, whereas M2 showed it as approximately equal proportions of the inwards and outwards rotamers. Some of the orientations of other surface residues of M1-M4 were also altered compared with the WT, although none, with the exception of N62D, were in the vicinity of the active site. While there were variations in the water network among the mutants, it was difficult to make meaningful, direct comparisons owing to differences in resolution between data sets. There was extra electron density in the structure of M4, where it appeared to fit a D130E substitution, but this was not included in any of the mutants. Gene and protein analysis did not support any substitution at this position and the extra electron density remains unmodelled. Representative portions of the electron density maps for M1-M4 are shown in Supplementary Fig. 3.

Extreme haloterance of M4 supported by thermal unfolding. The effect of added salts, ILs and the denaturants, $\mathrm{GuHCl}$ and urea on the thermal unfolding values of WT and M1-M4 enzymes were assessed over the $\mathrm{pH}$ range 7-11 using differential scanning fluorimetry (DSF). Of the buffers employed, Tris- $\mathrm{HCl}$ in the $\mathrm{pH}$ range 8-9 provided the highest thermal unfolding values $\left(T_{\mathrm{h}}\right)$ and the results presented in this section pertain to experiments conducted in $50 \mathrm{mM}$ Tris- $\mathrm{HCl} \mathrm{pH} \mathrm{8.5.} \mathrm{The} T_{\mathrm{h}}$ values for the enzymes in the buffer conditions were WT $67.5^{\circ} \mathrm{C}, \mathrm{M} 1$ $66.5^{\circ} \mathrm{C}, \mathrm{M} 250.0^{\circ} \mathrm{C}, \mathrm{M} 350.0^{\circ} \mathrm{C}$ and $\mathrm{M} 442.5^{\circ} \mathrm{C}$.

The addition of $\mathrm{Na}_{2} \mathrm{SO}_{4}$ at all concentrations tested increased the thermal unfolding temperatures for M2-M4 with M4 most 


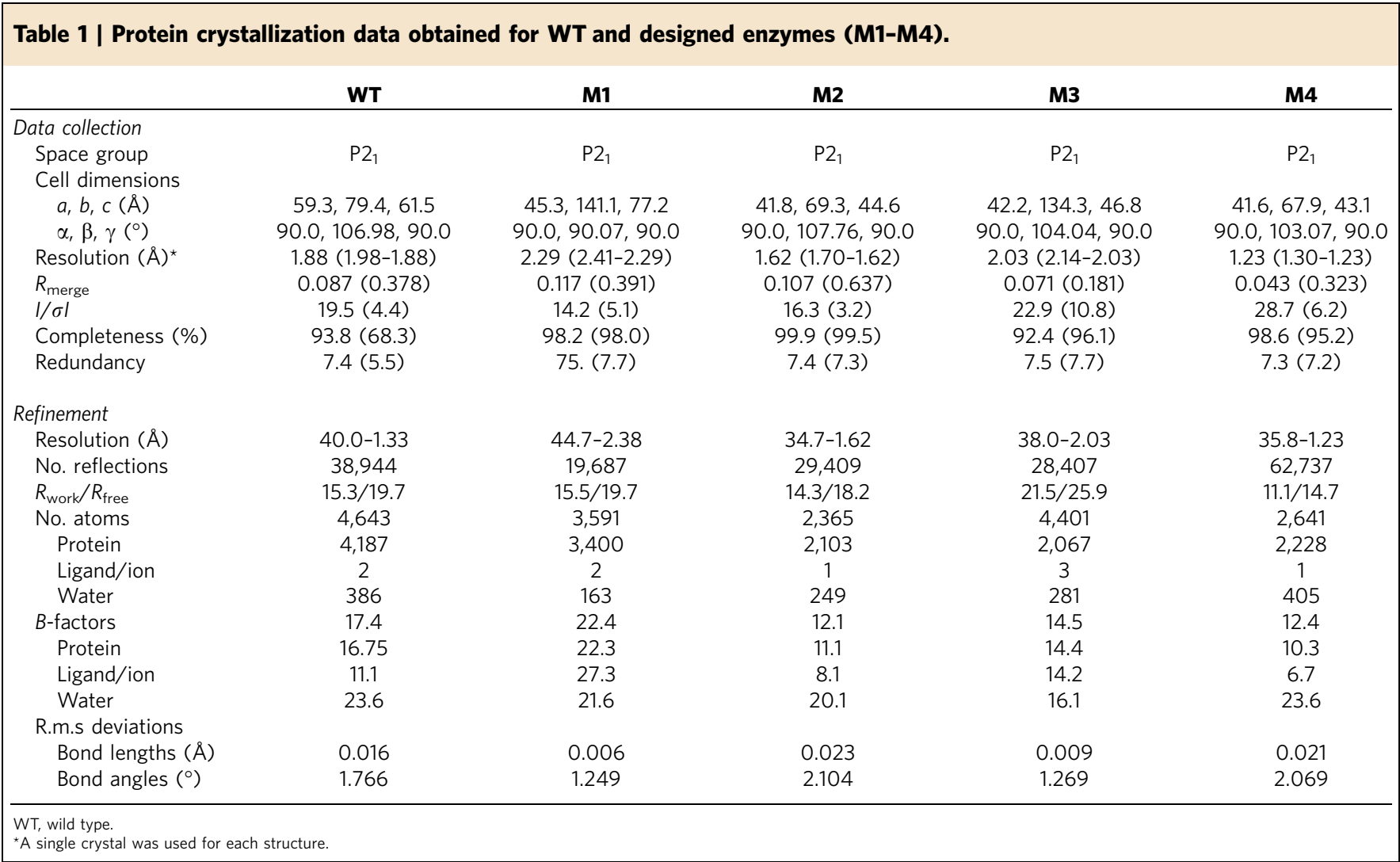

positively affected (Fig. 1a). At $1,800 \mathrm{mM}$, the unfolding temperature for $\mathrm{M} 4$ increased by $22.5^{\circ} \mathrm{C}$, which brought its unfolding temperature to the highest $T_{\mathrm{h}}$ observed for WT. Conversely, the unfolding temperatures for WT were reduced by up to $2{ }^{\circ} \mathrm{C}$ in the presence of $\mathrm{Na}_{2} \mathrm{SO}_{4}$ with $\mathrm{M} 1$ showing an intermediate response. The effect of $\mathrm{NaCl}$ on unfolding temperature was investigated in hypersaline conditions, that is, normal seawater has very $\sim 600 \mathrm{mM} \mathrm{NaCl}$ and the lowest concentration tested here was $1,000 \mathrm{mM}$. Similarly, addition of $\mathrm{NaCl}$ to the thermal unfolding analysis resulted in contrasting effects for WT and M4; the $T_{\mathrm{h}}$ for WT was reduced as the concentration of $\mathrm{NaCl}$ increased, whereas $\mathrm{M} 4$ was increasingly stabilized with increasing $\mathrm{NaCl}$ concentration (Fig. 1b). The unfolding temperatures for the intermediate enzymes (M1-M3) showed a transitional relationship, where M3 was unaffected by added $\mathrm{NaCl}$ whereas the effects on $\mathrm{M} 1$ and M2 were between that for WT and M3. Among the sodium salts tested, the most negative effect on unfolding temperature was caused by $\mathrm{NaNO}_{3}$ which substantially reduced $T_{\mathrm{h}}$ for all the carbonic anhydrases in a concentration-dependent manner except for M4 whose $T_{\mathrm{h}}$ was barely affected by the addition of the salt up to $2 \mathrm{M}$ (Fig. 1c).

Four ILs were tested against the WT and M1-M4 enzymes in $50 \mathrm{mM}$ Tris- $\mathrm{HCl}$ at $\mathrm{pH} 8.5$. There was a clear difference in the effect of the addition of EtOH-AF to the enzymes; $T_{\mathrm{h}}$ values for WT and M1 were reduced with increasing IL concentration, whereas this caused an increasingly positive effect on unfolding temperature for M2 through to M4 (Fig. 1d). The effects of adding ethyl-AF, ethyl-NO3 and DMI-DMP on WT and the designed enzymes were similar, all ILs reduced $T_{\mathrm{h}}$ for WT and M1-M3 and the effect increased with increasing concentration. However, the $T_{\mathrm{h}}$ for M4 was much less affected by IL addition than the other enzymes and was even positively affected by the addition of ethyl-AF (Supplementary Fig. 4a-c).
The addition of denaturants urea and $\mathrm{GuHCl}$, to enzymes in the DSF analysis affected the thermal unfolding temperatures for WT and M1-M3 enzymes similarly, that is, the change in $T_{\mathrm{h}}$ values were similarly negative for all enzymes with addition of denaturant (Supplementary Fig. 5a,b). However, the $T_{\mathrm{h}}$ for M4 was affected less by $\mathrm{GuHCl}$ than the other enzymes, although similarly affected by urea.

While the thermostability of M4 was increased by the addition of salts to the basic buffer condition, the unfolding temperatures of any of the carbonic anhydrases did not exceed that for native bCAII in buffer.

Secondary structure stability is greater for M4 in SDS. WT was more susceptible than M4 to the secondary structure-disrupting effects of SDS as observed by circular dichroism (CD) spectroscopy (Fig. 2). Most $\beta$-sheet structure was absent and additional $\alpha$-helix was formed in WT enzyme exposed to $0.0375 \%$ w/v SDS, whereas disruption to secondary structure was relatively minor in M4 at the same concentration (Fig. 2). Preincubation of the enzymes for $60 \mathrm{~min}$ before $\mathrm{CD}$ analysis yielded a very similar pattern of secondary structure disruption to that where spectra were read immediately following SDS exposure (Supplementary Fig. 6). Conversely, the loss of secondary structure in WT, M3 and M4 by the addition of $\mathrm{GuHCl}$ was similar at each concentration tested between 250 and $5,000 \mathrm{mM}$ (Supplementary Fig. 7).

Catalytic activity of M4 is increased in high salt. The catalytic activities of WT and engineered enzymes M1-M4 were assessed by measuring activity through standard assays in the presence and absence of a range of salts and denaturants. 4-NPA esterase catalytic rates of M1-M4 measured under standard assay conditions and low ionic strength $(I=0.2 \mathrm{M})$ were reduced 

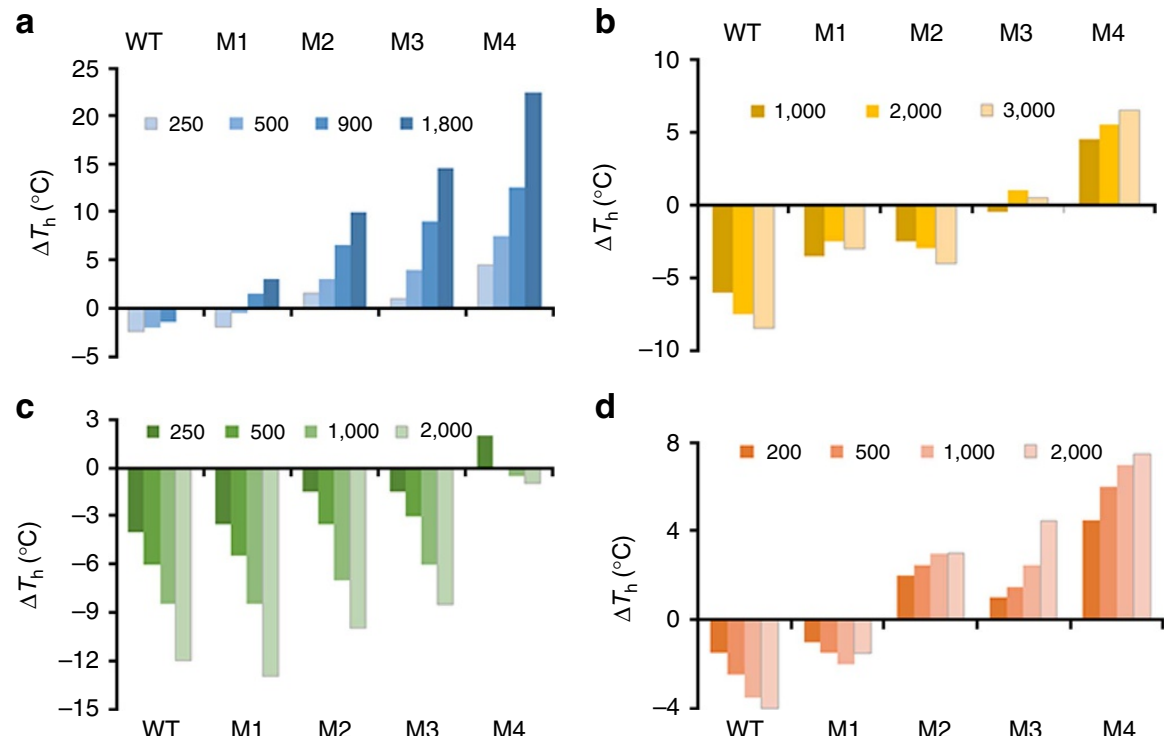

d

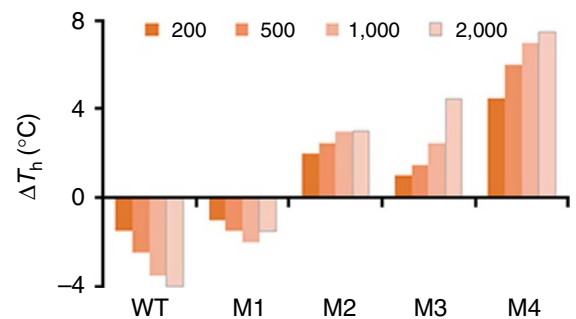

Figure 1 | Thermal unfolding analyses of WT and M1-M4 carbonic anhydrases. Experiments were performed in the presence of increasing concentrations of (a) $\mathrm{Na}_{2} \mathrm{SO}_{4}$, (b) $\mathrm{NaCl}$, (c) $\mathrm{NaNO}_{3}$ and (d) ionic liquid EtOH-AF. For each enzyme, thermostability is indicated by the difference in thermal unfolding value $\left(T_{\mathrm{h}}\right)$ obtained by DSF in the presence of salt and $50 \mathrm{mM}$ Tris- $\mathrm{HCl}$ buffer $\mathrm{pH} 8.5$ versus buffer only.

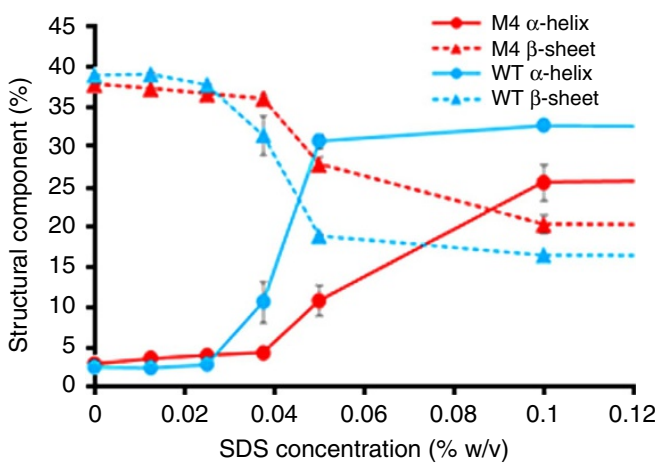

Figure 2 | Circular dichroism analysis of WT and M4 in SDS. Mean percentage ( \pm s.d.) $\alpha$-helix and $\beta$-sheet secondary structure content in WT and M4 carbonic anhydrase with increasing concentrations of the detergent $\mathrm{SDS}(\% \mathrm{w} / \mathrm{v})$ in $10 \mathrm{mM}$ Tris- $\mathrm{HCl} \mathrm{pH} 8$ as determined by circular dichroism spectroscopy.

compared with WT, as shown in Table 2. Both M1 and M2 contained six substitutions with each change exclusive to each variant, but the enzymes displayed similar catalytic activities in low ionic strength conditions. However, only M1 carried the N62D substitution and its catalytic activities were $86 \%$ and $61 \%$ of the WT activity for $\mathrm{CO}_{2}$ hydration and esterase, respectively (Table 2). M3 and M4, having the largest numbers of amino acid changes, exhibited the lowest esterase activities under these conditions with M4 reduced by $\sim 66 \%$ compared with WT. Esterase activities determined over points within the $\mathrm{pH}$ range of 6.8-8 showed maximal activity at $\mathrm{pH} 8$ for all enzymes, suggesting that there has been no change to the properties of the active nucleophile and adjacent residues (Supplementary Fig. 8).

The addition of sodium salts of sulfate, chloride and nitrate to the 4-NPA assay buffer had potent effects on the apparent activities. Addition of $\mathrm{Na}_{2} \mathrm{SO}_{4}$ over the concentration range 250-1,500 $\mathrm{mM}$ had a strong positive effect on the catalytic activities of M3 and M4 in particular, and these increases were significantly greater compared with the increases for WT

\begin{tabular}{|c|c|c|}
\hline $\begin{array}{l}\text { CAll } \\
\text { enzyme }\end{array}$ & $\begin{array}{c}\text { Esterase activity }{ }^{\star} \\
\left(\mu \mathrm{mol} \mathrm{min}{ }^{-1} \mathrm{nmol}^{-1}\right)\end{array}$ & $\begin{array}{c}\mathrm{CO}_{2} \text { hydration } \\
\left(\mathrm{M}^{-1} \mathrm{~s}^{-1}\right) \times 10^{8}\end{array}$ \\
\hline$\overline{\text { WT }}$ & 2.12 & 1.198 \\
\hline M1 & 1.30 & 1.037 \\
\hline M2 & 1.16 & 1.034 \\
\hline M3 & 0.71 & 0.928 \\
\hline M4 & 0.71 & 0.957 \\
\hline
\end{tabular}

(Fig. 3a). Esterase activity for $\mathrm{M} 4$ was highest where $\mathrm{Na}_{2} \mathrm{SO}_{4}$ was added at $1,500 \mathrm{mM}$ and restored the enzyme's initial velocity to for the same as WT under identical conditions. Sodium chloride added to the assay mixture at concentrations of $750 \mathrm{mM}$ and below inhibited esterase activity of all enzymes by up to $40 \%$ with M4 being the least affected (Fig. 3b). At 2,500 mM and above, the esterase activity of M1-M4 enzymes increased above activities measured in the absence of $\mathrm{NaCl}$ with significant increases in activity for M3 and M4 (Fig. 3b). However, there was no condition identified where the activities of M1-M4 exceeded that of WT under basic buffer conditions.

Sodium nitrate is an inhibitor of carbonic anhydrase II enzymes as it is isoelectronic with carbonate ${ }^{16}$ and all enzymes were inhibited by the addition of $\mathrm{NaNO}_{3}$ at concentrations ranging from 50 to $3,000 \mathrm{mM}$. However, in terms of percentage of activity remaining compared with the control condition for each enzyme, M3 and M4 showed a significantly lower susceptibility to nitrate inhibition (Fig. 3c). That is, the concentration to inhibit activity by $50 \%$ (IC50) measured over range of substrate concentrations was significantly higher for M3 and M4 (Supplementary Table 2). Furthermore, the IC50 value increased with increased number of acidic residue substitutions on the carbonic anhydrase surface suggesting a strong influence of electrostatic interactions on the potency of nitrate inhibition. 
a

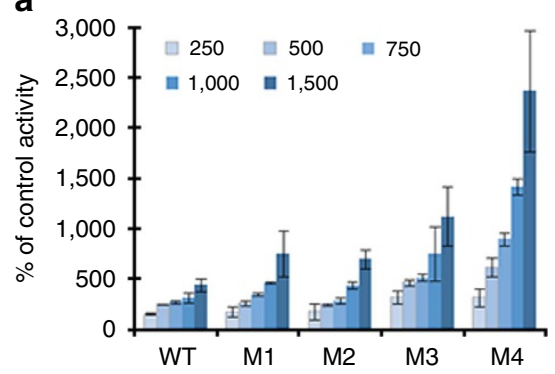

C

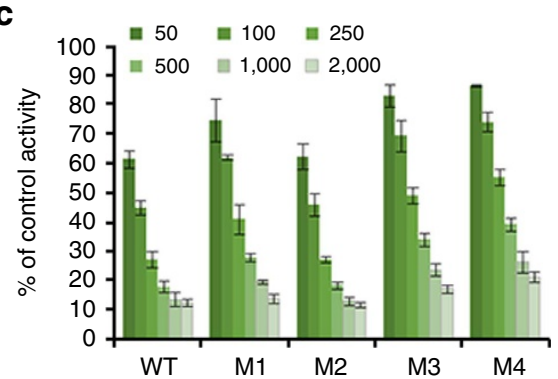

b

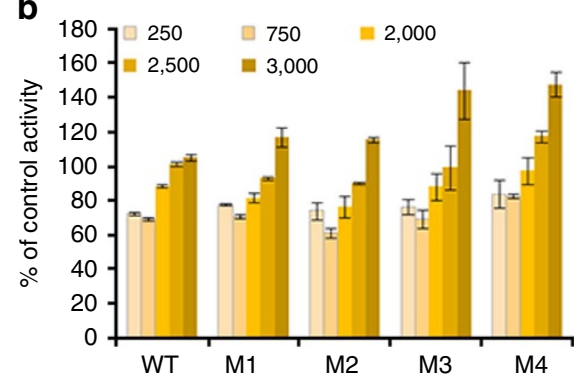

d

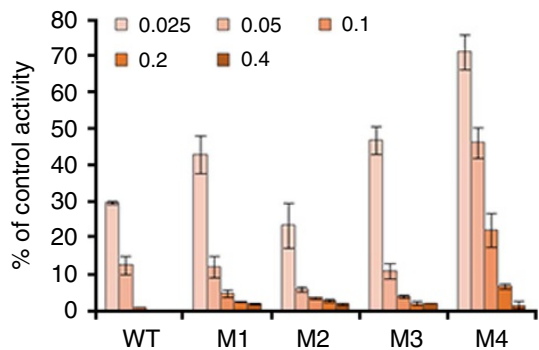

Figure 3 | Effect of salts and denaturants on esterase activity of WT and M1-M4. Graphs indicate percentage of control activity \pm s.d. for enzymes in (a) $\mathrm{Na}_{2} \mathrm{SO}_{4}$, (b) $\mathrm{NaCl}$, (c) $\mathrm{NaNO}_{3}$ and (d) SDS. Salts are shown as millimolar concentrations except SDS which is \% w/v. Control activity refers to the activity of the individual enzyme in the absence of added salt.
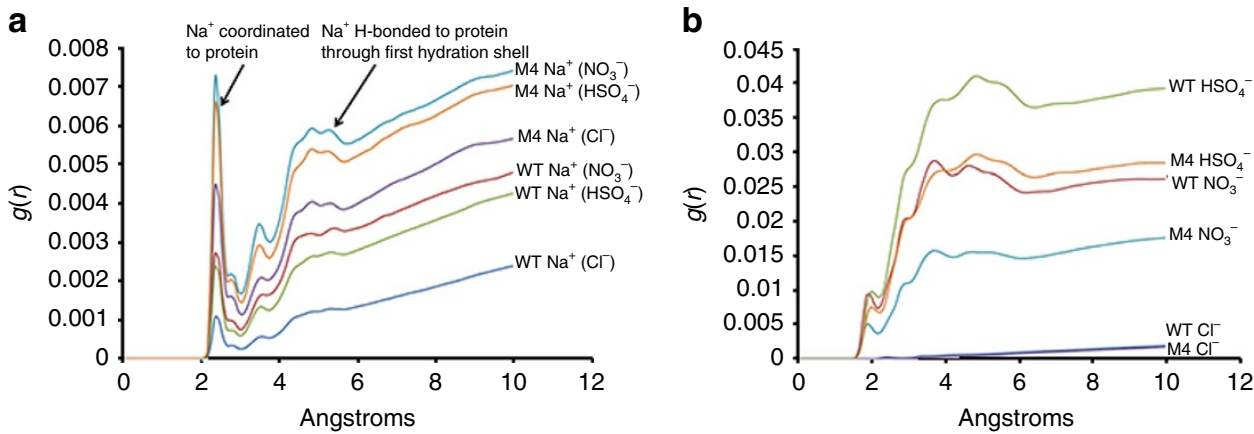

Figure 4 | Radial distribution functions $(\boldsymbol{g}(\boldsymbol{r}))$ for cations and anions against whole enzymes. RDFs are shown from the MD simulations with WT and M4 across the three salt conditions for $\mathrm{Na}^{+}$(a) and for the anions (b) calculated over 50,000 frames of the 500 ns production trajectory.

Addition of the protein-denaturing ionic detergent SDS negatively affected the activities of all the enzymes; however, the esterase activity of M4 was least affected and its activity was significantly higher than the other carbonic anhydrases in the presence of SDS up to $0.2 \% \mathrm{w} / \mathrm{v}$ (Fig. 3d). The presence of $\mathrm{GuHCl}$ $(250-5,000 \mathrm{mM})$ in the assay mixture did not discriminate between the WT and M3 as they were similarly inhibited but M4 was slightly more affected by the presence of the denaturant (Supplementary Fig. 9).

Role of $\mathrm{Na}^{+}$in stabilizing M4 structure. The molecular dynamics simulations revealed a complex variety of interactions between the cations, anions and enzymes. In general, $\mathrm{Na}^{+}$ cations interacted with more sites on M4 than with WT. The longest-lived $\mathrm{Na}^{+}$residence times, that is, the time the cation was directly associated with the enzyme, occurred where chelating environments existed such as the presence of three or more coordinating oxygen atoms usually provided by a combination of Glu and Asp side chains and main chain carbonyl oxygen atoms.
The radial distribution functions (RDFs) were calculated for the interaction of $\mathrm{Na}^{+}$and enzyme surfaces from the $\mathrm{NaCl}, \mathrm{NaNO}_{3}$ and $\mathrm{NaHSO}_{4}$ simulations. Four distinct association distances were apparent across the three salt simulations at 2.2, 2.7, 3.5 and $\sim 4.4-5.1 \AA$, with the first and last of these being the major peaks corresponding to directly coordinated $\mathrm{Na}^{+}$and hydrogenbonded fully hydrated $\mathrm{Na}^{+}$, respectively (Fig. 4). Comparison between the whole enzymes showed there was a clear increase in association of $\mathrm{Na}^{+}$with M4 over WT in all salt conditions.

Analysis of the RDFs for the anions and proteins showed significantly lower populations of $\mathrm{NO}_{3}^{-}$and $\mathrm{HSO}_{4}^{-}$associating with M4 than with WT; however, this difference was not observed for $\mathrm{Cl}^{-}$, which showed almost no differences between the enzymes (Fig. 4). The shortest association peaks for $\mathrm{NO}_{3}^{-}$and $\mathrm{HSO}_{4}^{-}$occurred at $\sim 1.9 \AA$, whereas that for $\mathrm{Cl}^{-}$was at $2.3 \AA$. There were four additional association peaks for $\mathrm{NO}_{3}^{-}$and $\mathrm{HSO}_{4}^{-}$indicating water-mediated interactions; however, they were slightly less well-defined for $\mathrm{HSO}_{4}^{-} \cdot \mathrm{Cl}^{-}$showed two distinct peaks but at much lower levels of association compared with the polyoxoanions in their respective systems. 
While the radius of gyration (Supplementary Fig. 10) for each protein over the course of the simulations indicated that there were no major perturbations to the secondary structure, as did visual inspection, the RMSD's for the M4 simulations in both $\mathrm{NaNO}_{3}$ and $\mathrm{NaHSO}_{4}$ began to gradually increase after $\sim 300 \mathrm{~ns}$, the greatest being $\sim 3.8 \AA$ for $\mathrm{NaHSO}_{4}$ at $\sim 570 \mathrm{~ns}$. Interestingly, the same effect was not observed for the WT simulations. Overlaps of the covariance matrices for the first and second halves of the 500 ns production trajectory (Supplementary Table 3) suggest there may be some motions at much longer timescales that have not yet been fully sampled. The largest RMSD for the $\mathrm{M} 4 / \mathrm{NO}_{3}^{-}$system is attributable to an outwards shift of the loop regions consisting of residues 198-204, whereas for the $\mathrm{M} 4 / \mathrm{HSO}_{4}^{-}$system, it is primarily because of flexibility in the $\mathrm{N}$-terminal region (approximately the first 10 residues) of the protein with a smaller outwards shift in the 198-204 loop compared with $\mathrm{M} 4 / \mathrm{NO}_{3}^{-}$. A more detailed analysis of the RDFs of $\mathrm{Na}^{+}$with each mutated residue was performed and showed, for the majority of cases, very consistent association patterns both between the two halves of each simulation (Supplementary Figs 11-13). The greatest consistency was seen in the $\mathrm{M} 4 / \mathrm{HSO}_{4}^{-}$system, which had also showed the greatest departure from the original structure in terms of backbone RMSD, indicating that there is sufficient sampling over the $500 \mathrm{~ns}$ to adequately capture the dominating cation/anion/protein associations. In the $\mathrm{M} 4 / \mathrm{Cl}^{-}$system there were discrepancies between the two halves of the simulation in the $\mathrm{Na}^{+}$associations with $\mathrm{D} 8$, whereas in the $\mathrm{M} 4 / \mathrm{NO}_{3}^{-}$system the main differences were in D8, D36, D62 and E238. The transient proximity of D62 and E238 to the flexible $\mathrm{N}$-terminal region (which also contains D8) provides a highly changeable $\mathrm{Na}^{+}$coordination environment, explaining the RDF differences at these residues. However the difference for D36, which is located in the centre of a loop on the opposite face to the active site and has no chelating partners, is due to randomly alternating 'inward' and 'outward' rotamers of this residue, which has it sharing a $\mathrm{Na}^{+}$cation with D110 in the latter conformation only, and is not associated with any secondary structural movement. The longest-lived, consistent direct cation associations were at E169 across the $\mathrm{Cl}^{-}$, $\mathrm{NO}_{3}^{-}$and $\mathrm{HSO}_{4}^{-}$simulations for $\mathrm{M} 4$, where $\mathrm{Na}^{+}$coordination was, interestingly, shared with the carbonyl oxygen atom of W5 despite the flexibility of the $\mathrm{N}$-terminus. From the area under the curve for all the RDFs across all simulations, it is clear that the most common modes of association of the cations with the protein surface are actually mediated through the first hydration shells of the cations.

\section{Discussion}

While it has been established that naturally occurring halophilic enzymes possess a combination of lower and smaller hydrophobic residue content, fewer lysine residues, reduced accessible solvent area and a negative surface charge compared with mesohalophiles ${ }^{2-6,13}$, here the sole basis of rational enzyme design was substitution of surface residues to produce enzymes with extreme halotolerance. Up to 18 amino acid substitutions were made to the enzyme surface of bCAII, but this did not significantly alter the secondary structure, catalytic activity or stability of the designed enzymes, compared with WT, in the presence of added salts. Surface residues that were not involved in significant interactions were targeted for substitution and this approach resulted in the loss of up to three Lys out of a total of 18 in the protein and a minor reduction in solvent-accessible surface area in the designed proteins. Traditionally, halophilic enzymes would be sourced from naturally occurring salt-tolerant organisms such as the alga Dunaliella salina; however, this approach does not always yield useful biocatalysts. Recombinant expression of halophilic enzymes in mesohalophilic organisms can be difficult because of their instability in low salt conditions ${ }^{17}$ and for a carbonic anhydrase from $D$. salina, the component subunits lacked haloterance and $\mathrm{CO}_{2}$ hydration activity ${ }^{18}$. Moreover, other rational design approaches that target surface residues with 'supercharging' algorithms for increasing protein stability ${ }^{19}$ have had limited application to catalytic proteins and, to the best of our knowledge, supercharged proteins have not been reported to be halotolerant. In light of recent crystallographic findings showing that increased numbers of acidic surface residues disrupt ordered pentagonal water networks ${ }^{20}$, it is perhaps unsurprising that the mutants' thermostabilities were reduced in low-salt conditions compared with WT. Our approach to rational design for halotolerance, which involves selective conversion of surface residues to acidic residues and distributing residue substitutions across the surface, has meant the resulting enzymes were not as destabilized as may be expected by altered electrostatics ${ }^{21}$ or because of the large number of residue changes ${ }^{22}$.

Undertaking the residue substitutions in the WT enzyme in stages and investigating the separate and combined substitutions allowed the intermediate enzymes with fewer substitutions to be assessed. Generally, the salt tolerance of enzymes increased with increasing number of substitutions, as measured by catalytic activity and thermostability, with M4 showing the greatest halotolerance. In low-salt conditions $(<1 \mathrm{M})$, M3 and M4 were less stable than WT as demonstrated by both lower unfolding temperatures and catalytic activities. The phenomenon of reduced stability in halophilic proteins in low-salt conditions has been attributed to either a reduction in the hydrophobic effect ${ }^{4}$ or repulsive electrostatic interactions ${ }^{19}$. A significant change in the hydrophobic effect is unlikely for M3 and M4 compared with WT as the buried hydrophobic core residues of the proteins were unaltered in the designed versions.

Significantly, M3 and M4 were stabilized by the addition of salts to the media for thermal unfolding analysis (Fig. 1) and the extent of stabilization followed the Hofmeister series, that is, anions of high charge density, such as sulfate, were more effective in stabilizing M1-M4 followed by chloride then nitrate, with all salts sharing sodium as the cation. Indeed, the thermostability regained by $\mathrm{M} 4$ in high- $\mathrm{Na}_{2} \mathrm{SO}_{4}$ and $-\mathrm{NaCl}$ solutions (Fig. 1a,b) suggests WT was transformed into an obligate halophile through engineering of its surface residues. The increase in the thermostabilities of M1-M4 in the presence of salts was mirrored by the increased esterase activity of the enzymes in the presence of sodium salts of sulfate and chloride relative to WT (Fig. 3). Indeed, the activities of M3 and M4 in 1,500 mM sulfate were significantly enhanced relative to WT and well in excess of the 'salting out' effect of substrate observed previously by Steiner and Linskog ${ }^{23}$. In that study, $\mathrm{Na}_{2} \mathrm{SO}_{4}$ at concentrations of up to $1 \mathrm{M}$ caused a marked increase in 4-NPA hydrolysis activity by human CAII and this was attributed to a salting out effect of the dissolved substrate with little or no salt effect on the enzyme active site residues. In that study, the activity increase reached a plateau at $\mathrm{pH}$ values above 8 in the presence of $1,000 \mathrm{mM} \mathrm{Na}_{2} \mathrm{SO}_{4}$ and this was approximately four-fold higher than the rate in the absence of salts, which was consistent with the WT increase in Fig. 3a. Sodium nitrate, together with most monovalent anions, inhibits carbonic anhydrase through binding to the active site at a position close to the metal ion and displaces the metal-coordinated hydroxide ion involved in the catalytic reaction ${ }^{24}$. However, despite the active site residues remaining unaltered in M1, M3 and M4, sodium nitrate was significantly less inhibitory of the esterase reaction of these enzymes compared with WT. This could be due to the decreased apparent local 
concentration of nitrate around the enzyme, as observed in the molecular dynamics (MD) simulations (Fig. 5). We also note that an increased concentration of $\mathrm{Na}^{+}$ions around the active site in the MD simulations prevents nitrate from otherwise occupying the area (Fig. 5 c,d).

The engineered halotolerant enzymes were also more resistant to the destabilizing effects of selected ILs and denaturants such as SDS that cause unfolding of proteins through the disruption of secondary structural elements ( $\alpha$-helices and $\beta$-sheets). SDS denatures proteins through disruption of tertiary structure via unfolding and chain expansion, depending on the micelle concentration $^{25}$. SDS was less effective in disrupting the structure and catalytic activity of M4 presumably because of the repellent charge effects on the surface of the engineered enzyme that reduced access of negatively charged micelles to the hydrophobic core. In addition, the number of exposed hydrophobic residues is reduced in M4, hence providing fewer points of access for the SDS hydrophobic tail. However, for denaturants such as urea (neutral) and $\mathrm{GuHCl}$ (positively charged), the engineered enzymes were similarly susceptible as the WT enzyme.

The salt ion interactions were explored with the WT and M4 enzymes using molecular dynamics. Highly specific interactions with particular groups of residues were noted over the course of the simulations. As expected, an increase in surface acidic residues in M4 had the subsequent effect of increasing the population of $\mathrm{Na}^{+}$at the surface and also in secondary shells connected to the surface by waters of hydration. This had a shielding effect whereby $\mathrm{Na}^{+}$occupied significant regions of surface-space for prolonged periods and prevented the approach of anions (Fig. 5). This effect is clear from the $\mathrm{RDFs}$ for $\mathrm{HSO}_{4}^{-}$ and $\mathrm{NO}_{3}^{-}$, but was not observed for $\mathrm{Cl}^{-}$. This could be due to the significantly smaller hydrodynamic radius of $\mathrm{Cl}^{-}$allowing a more efficient packing of hydrated $\mathrm{Na}^{+} \mathrm{Cl}^{-}$layers around the surface, somewhat negating the exclusion effect of $\mathrm{Na}^{+}$. A comparison of the $\mathrm{Cl}^{-}$distributions around WT and M4 shows that $\mathrm{Cl}^{-}$can approach the surface in a much more diffuse area
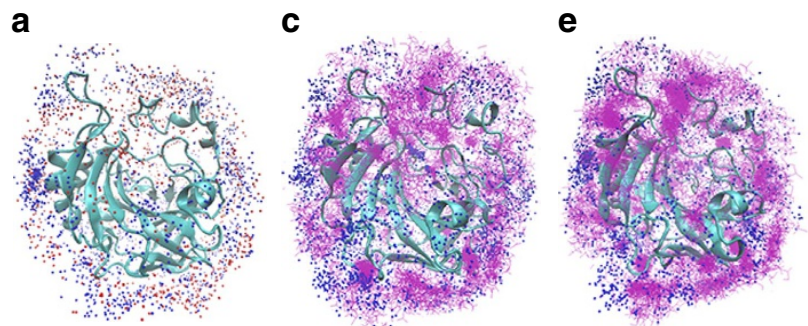

b

d
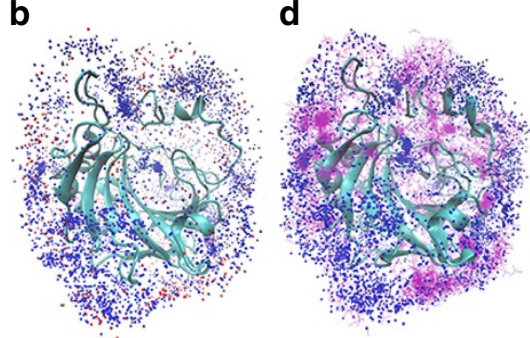

f

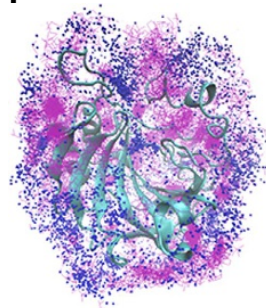

Figure 5 | Overlays showing the distribution of cations and anions within $3 \AA$ of the enzyme surface. The overlays incorporate anions and cations from 500 frames spanning the 500 ns MD production trajectories. (a,b) $\mathrm{NaCl}$ with WT and $\mathrm{M} 4$, respectively; (c,d) $\mathrm{NaNO}_{3}$ with $\mathrm{WT}$ and $\mathrm{M} 4$, respectively; and (e,f) $\mathrm{NaHSO}_{4}$ with $\mathrm{WT}$ and $\mathrm{M} 4$, respectively. $\mathrm{Na}^{+}$cations are depicted as dark blue spheres, $\mathrm{HSO}_{4}^{-}$and $\mathrm{NO}_{3}^{-}$anions are depicted as purple lines and $\mathrm{Cl}^{-}$anions are depicted as orange spheres. for WT, whereas M4 shows much more well-defined pockets where $\mathrm{Cl}^{-}$can reside with much longer residence times (Fig. 5).

$\mathrm{RDFs}$ for the individual substituted residues introduced into M4 and not present in WT showed a clear preference of some for $\mathrm{Na}^{+}$over others. This was largely dictated by coordination number, with chelating environments strongly favouring long residence times. Acidic residues isolated from chelating partners were still able to attract $\mathrm{Na}^{+}$cations; however, the interactions were highly transient, usually with a single water being displaced from the first $\mathrm{Na}^{+}$hydration sphere and then rapidly replaced from the bulk solvent. The most significant observation from the $\mathrm{RDF}$ is that the dominant associations of the cations with the new acidic residues were actually those mediated through the hydration shells of the cations. These were complex and dynamic associations whose prevalence suggests that it is actually the hydrated cations, specifically, their ordered hydration shells, that act to re-establish a stabilizing surface-water network that was disrupted when the naturally evolved surface was altered. Future halotolerance design strategies should take this into account; however, it would be necessary to carry out additional calculations using a more sophisticated water model and timesteps of finer resolution to further investigate the nature of the hydrated cations' influence on the broader water network.

The many biophysical and compositional features of halophilic enzymes that distinguish them from mesohalophiles have been drawn from comparative genome, proteome and crystal structure analyses. In contrast to suggestions that large differences in accessible solvent area, non-polar surface area or absence of large hydrophobic amino acids are the important features that allow halophilic enzymes to function optimally in high-salt environments, we have found that increasing the number and distribution of surface acidic groups alone is sufficient to impart this characteristic. The design principles demonstrated here could be readily applied to other mesohalophilic enzymes. Furthermore, we find that increased frequency and longevity of binding of cations to acidic residues on the halotolerant enzyme surface has the dual effect of stabilization of the surface structure and increased repulsion of anions.

\section{Methods}

Rational design of carbonic anhydrase for haloterance. The amino acid sequence of bovine carbonic anhydrase II (bCAII; NP_848667.1) was subjected to BLASTp analysis and the 50 best matching sequences (Supplementary Data 1) were aligned using ClustalW. In most cases, residue positions in bCAII that were most variable with respect to amino acid in the sequence alignment with other carbonic anhydrases were selected as candidates for mutation as they were considered to be the most tolerant of variation (Supplementary Fig. 14). Preference of site for mutation was given to residues that were on the surface of the protein as determined by examination of the bCAII crystal structure (PDB: 1V9E) and not

Table 3 | Amino acid substitutions generated for rationally designed carbonic anhydrase II enzymes examined in this study.

Protein Amino acid substitutions compared with WT as expressed

M1 G8D, K36D, V50D, N62D, Q136E and L238E

M2 N24D, V39D, R57D, Q74E, K169E and N252D

M3 G8D, N24D, K36D, V39D, V50D, R57D, N62D, Q74E, Q136E, K169E, L238E and N252D

M4 G8D, K18E, N24D, K36D, V39D, V50D, R57D, N62D, Q74E, T85D, Q136E, K169E, N177D, N186E, Q220E, L238E, N252D and Q254E

WT, wild type.

${ }^{*}$ Cloning of WT and designed enzymes into the expression vector pET28 resulted in two additional residues at the $\mathrm{N}$-terminus of the protein sequence $(\mathrm{MG})$ relative to the native sequence, but the original numbering has been conserved here. 


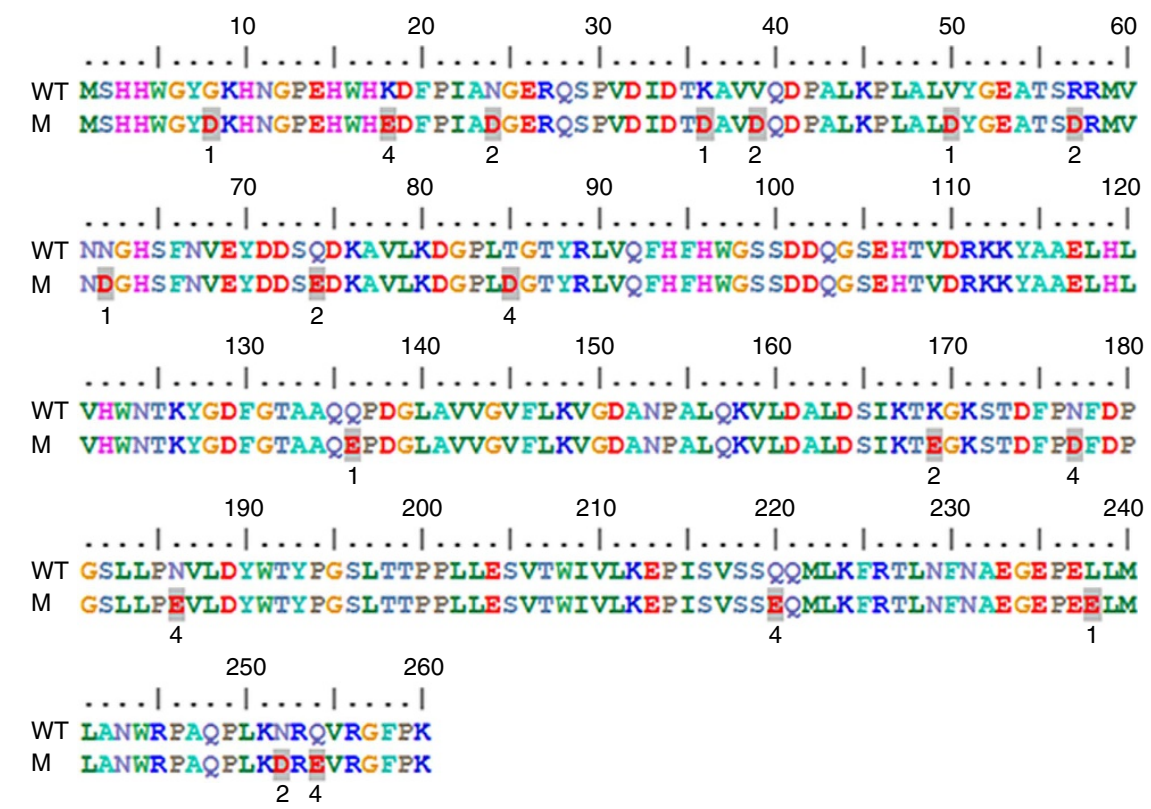

Figure 6 | Alignment of the WT amino acid sequence with the rationally designed, halotolerant enzymes (M). The shaded residues were altered in the designed sequences versus WT and the sequence where each substitution featured are given in the bolded number below, that is, the change is uniquely present in either M1, M2 or M4.
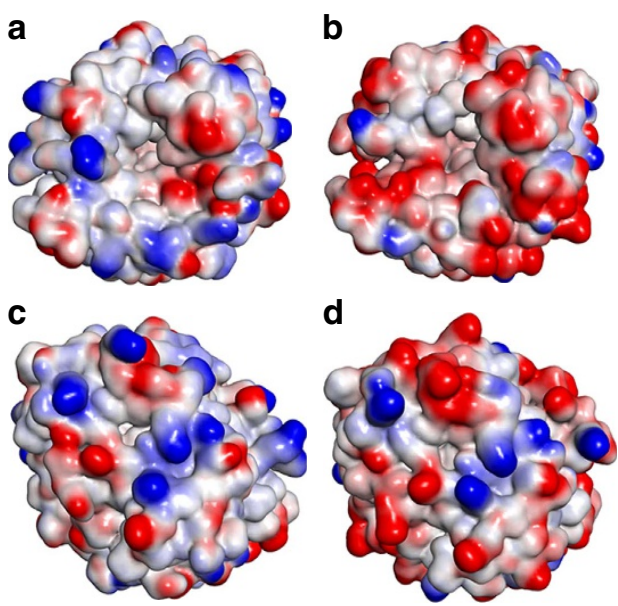

Figure 7 | Distribution of surface charge in WT and M4. Positive charges (blue) and negative charges (red) are projected onto a solvent-accessible surface (1.4 $\AA$ probe radius) of WT (a,c) and designed M4 (b,d) carbonic anhydrase II using an interpolated charge algorithm as implemented in Discovery Studio 3.5. The top images, looking directly into the active site pocket, are rotated $180^{\circ}$ around a vertical axis compared with the bottom images.

already involved in significant interactions such as salt bridges or hydrophobic interactions with adjacent residues to minimize potential negative impacts on stability. The decision of whether to mutate an existing residue, most usually neutral, to an acidic residue (Asp or Glu), was based largely on steric bulk of the side chain being replaced with some consideration being given to whether a new salt bridge could be generated or an existing one maintained. A total of 18 residues in total were selected for mutation; however, as we were unable to predict how many changes it may take to confer halotolerance to a salt-susceptible enzyme or how many residue changes would be tolerated by the enzyme structure before it became unstable or affected folding, the mutations were introduced in stages. Firstly, two independent sets of six amino acid substitutions each were introduced into WT (M1 and M2, Table 3) with a view to maximize the spatial arrangement across the enzyme's surface within each group and enable the assessment of stability and activity of each set. Following this, a combination set of these 12 mutations was also generated and assessed (M3). A final set of an additional six changes were added into the 12 changes already present in M3 to generate enzyme M4. The locations of the residue changes in the designed enzymes are summarized in the sequence alignment (Fig. 6) and the extent of change in surface charge for the M4 enzyme compared with WT is shown in Fig. 7.

Recombinant expression and purification. Native bCAII was purchased from Sigma Aldrich and was used as supplied or purified via IMAC affinity chromatography as described below. Recombinant bCAII (NM_178572.2), herein described as 'wild type', and the designed enzymes M1-M4 (Table 3) were synthesized in codon-optimized versions (Geneart, Life Technologies) and ligated in frame into pET28 using the XhoI and $\mathrm{NcoI}$ restrictions sites. The in-frame insertion resulted in the introduction of two additional non-native amino acids (MG) at the N-terminus and did not incorporate the histidine-tag. Plasmids with the correct insert were transformed into $E$. coli $\mathrm{BL} 21(\mathrm{DE} 3)^{*}$ strain, positive colonies were selected and cultures prepared for expression in autoinduction media. The DNA sequence of the plasmid insert coding for M4 was reconfirmed and the expressed M4 protein purified from two separate E. coli cultures was excised from SDS-polyacrylamide gel electrophoresis, trypsin digested and the peptide fragments analysed by Agilent electrospray LC-MS. Peptides were matched to sequences in the NCBI non-redundant protein database and the predicted protein M4 using Spectrum Mill software. Peptides for the expressed M4 sequence completely matched the predicted sequence. At the completion of the incubation period, the cells were pelleted, lysed in buffer containing $0.5 \mathrm{mM} \mathrm{ZnCl}_{2}$ (WT only) and bound to a Ni-NTA column for purification by fast protein liquid chromatography. The WT and engineered enzymes were eluted with an imidazole gradient and the fractions containing carbonic anhydrase were dialysed against $50 \mathrm{mM}$ Tris- $\mathrm{HCl}$ at $\mathrm{pH} 7.5$ containing $10 \mu \mathrm{M} \mathrm{ZnCl} 2$ (except M4). For M4, dialysis against $\mathrm{ZnCl}_{2}$ was performed at $0.5 \mathrm{~mol} \mathrm{~mol}^{-1}$ enzyme. All characterization reported herein was performed on the $\mathrm{Zn}$-supplemented enzymes.

Crystallization of mutants. Thermal denaturation studies were used to select a formulation buffer $(50 \mathrm{mM}$ piperazine $\mathrm{pH} 5.5,50 \mathrm{mM} \mathrm{NaCl})$ for crystallization. M1-M4 were dialysed into this buffer then screened at approximately $20 \mathrm{mg} \mathrm{ml}^{-1}$ against a sparse matrix screen and an ammonium sulfate/Tris buffer screen based on the known crystallization conditions for bovine carbonic anhydrase II. Diluting the protein to $10 \mathrm{mg} \mathrm{ml}^{-1}$ and setting up against the JCSG + sparse matrix screen at $8^{\circ} \mathrm{C}$ gave crystals of $\mathrm{M} 1$ and $\mathrm{M} 3$, these were used to seed further screening experiments with the M2 and M4 protein also at $8^{\circ} \mathrm{C}$. Eventually, after several rounds of seeding or cross-seeding, where the droplets are seeded with a seedstock produced from crystals of another mutant, crystals were obtained for all four variants. All crystallization experiments were set up in droplets consisting of $150 \mathrm{nl}$ protein solution, $140 \mathrm{nl}$ reservoir solution, $10 \mathrm{nl}$ seedstock against $50 \mu \mathrm{l}$ of reservoir in SD-2 sitting drop plates (Molecular Dimensions, UK) and employing Phoenix (ARI, CA) and Mosquito (TTPLabtech, UK) automation to set up the droplets.

The crystallization conditions for the crystals used for data collection were as follows: M1: 30\% w/v PEG 1,500; M2: 5\% w/v PEG 1,000, 30\% w/v PEG 600, 
$100 \mathrm{mM}$ sodium MES pH 6, 10\% glycerol; M3: 25\% w/v PEG MME 2k, $200 \mathrm{mM}$ calcium acetate, $50 \mathrm{mM}$ Tris-HCl pH 8; and M4: 40\% w/v PEG 600, $100 \mathrm{mM}$ sodium citrate $\mathrm{pH} 5.5$.

X-ray crystal structures of mutants. X-ray data were collected at $100 \mathrm{~K}$ at the MX-1 beamline at the Australian Synchrotron ( $0.95370 \AA$ \&avelength). The crystals from each mutant were cryo-cooled in the nitrogen stream just using reservoir as the cryo-protectant. In each case, $3601^{\circ}$ oscillations were obtained for a total of $360^{\circ}$ of data. The data were indexed using $\mathrm{XDS}^{26}$, and scaled and truncated using SCALA/TRUNCATE ${ }^{27}$. Phaser ${ }^{28}$ was used for molecular replacement, using PDB 3 ML2 as the starting model. Models were refined using Refmac ${ }^{29}$ after rebuilding by hand using $\operatorname{Coot}^{30}$. Ramachandran statistics were as follows: M1: $92.9 \%$ favoured, $6.7 \%$ allowed and $0.4 \%$ outliers; M2: $93.9 \%$ favoured, $5.6 \%$ allowed and $0.4 \%$ outliers; M3: $93.2 \%$ favoured, $6.8 \%$ allowed and $0.0 \%$ outliers; and M4: $91.9 \%$ favoured, $7.1 \%$ allowed and $1.0 \%$ outliers.

Enzyme unfolding analysis. High throughput screening for thermostability of WT and designed enzymes was conducted in the presence of various buffers, salts, denaturing agents and IL solutions using DSF $^{31}$. The assay was performed in 96- or 384-well PCR plates in a final volume of $20 \mu \mathrm{l}$ containing enzyme $(\sim 0.3 \mu \mathrm{g})$, SYPRO dye $(0.3 \mu \mathrm{l}$ of a 1:10 dilution of the dye in water) and $19.4 \mu \mathrm{l}$ of the test solution. The plates were heated at $1{ }^{\circ} \mathrm{C} \mathrm{min}-1$ between 20 and $100{ }^{\circ} \mathrm{C}$ in a BioRad CFX96 (or CFX384) PCR machine and in each batch performance controls were included such as commercial bovine carbonic anhydrase (Sigma) in $50 \mathrm{mM}$ Tris- $\mathrm{HCl} \mathrm{pH} \mathrm{7.5,} \mathrm{lysozyme} \mathrm{and} \mathrm{dye} \mathrm{controls.} \mathrm{Each} \mathrm{enzyme} \mathrm{and} \mathrm{condition} \mathrm{was}$ measured in triplicate and the values were averaged.

The conditions tested included a buffer screen $(50 \mathrm{mM})$ over the $\mathrm{pH}$ range $7-11$ in $50 \mathrm{mM}$ Tris- $\mathrm{HCl}$. The following salts were added at the stated concentrations: $1,000-3,000 \mathrm{mM} \mathrm{NaCl} ; 250-2,000 \mathrm{mM} \mathrm{Na}_{2} \mathrm{SO}_{4} ; 500-3,000 \mathrm{mM} \mathrm{NaNO}_{3}$; and each of guanidinium hydrochloride $(\mathrm{GuHCl})$, urea, ethyl ammonium formate, ethyl ammonium nitrate, ethanol ammonium formate (EtOH-AF) and 1,3dimethylimidazolium dimethylphosphate (DmimDMP] at $50-2,000 \mathrm{mM}$

For each sample run, the unfolding curve shape, starting points and end points were examined and the temperature of hydrophobicity $\left(T_{\mathrm{h}}\right)$ was estimated as a function of $\mathrm{pH}$, salt concentration and the buffering or additive chemical. The value $T_{\mathrm{h}}$ has been previously shown to be highly correlated to the absolute melt temperature, $T_{\mathrm{m}}$ (ref. 32). Prior experience with the technique ${ }^{31}$ indicates the inherent variability in the experimental system is $\pm 1{ }^{\circ} \mathrm{C}$, such that $T_{\mathrm{h}}$ changes of $>1{ }^{\circ} \mathrm{C}$ are significant.

\section{Structure assessment by circular dichroism spectroscopy. Far UV CD} spectra were obtained at $1 \mathrm{~nm}$ intervals between 190 and $250 \mathrm{~nm}$ on a Chirascan spectrometer (Applied Photophysics) using a $0.2 \mathrm{~mm}$ path length quartz cell (20/O/Q/0.2, Starna) at $25^{\circ} \mathrm{C}$. Buffer for the analysis was $10 \mathrm{mM}$ Tris- $\mathrm{HCl} \mathrm{pH} 8$. Spectra of a blank solution, which contained all assay components except protein, were recorded for each additive concentration. Protein concentration was adjusted to achieve optimal absorbance (1.3-1.6 AU) between 209 and $220 \mathrm{~nm}$. Blank and sample spectra were each measured in triplicate; mean absorbance for blank spectra were subtracted from mean sample absorbance to derive final CD spectra. $\alpha$-Helix and $\beta$-sheet content of enzymes in solution in the presence and absence of $\mathrm{GuHCl}$ $(250-5,000 \mathrm{mM})$ or SDS $(0.01-0.5 \% \mathrm{w} / \mathrm{v})$ were estimated using the program K2D3 (ref. 33) using the obtained CD spectra values. Denaturant was added to enzymes before CD analysis or pre-incubated with enzymes for 1 or $24 \mathrm{~h}$.

Catalytic activity and effect of salts and inhibitors. Carbonic anhydrase esterase activity was measured by the spectrophotometric method of Pocker and Stone ${ }^{34}$ with 4-nitrophenyl acetate (4-NPA) as substrate with the following modifications: buffer was $50 \mathrm{mM}$ HEPES $\mathrm{pH} 8$ containing $50 \mathrm{mM} \mathrm{Na}_{2} \mathrm{SO}_{4}$ (ionic strength $(I)=0.2 \mathrm{M})$. Production of 4-nitrophenol was monitored at $405 \mathrm{~nm}$ over $10 \mathrm{~min}$ at $25^{\circ} \mathrm{C}$ using a Molecular Devices SpectraMax Plus spectrophotometric plate reader and the concentration of 4-nitrophenol product determined by calibration curves prepared over a $0.01-0.25 \mathrm{mM}$ concentration range. Salts, detergents, denaturants and ILs that were assessed for their effect on activity, were fully mixed into the assay buffer before the addition of substrate to initiate the reaction. $\mathrm{Na}_{2} \mathrm{SO}_{4}$ (1 M final concentration) had no effect on the absorbance measurement for 4-nitrophenol $(0.1 \mathrm{mM})$ when added to the assay buffer. Appropriate control samples lacking enzyme or substrate were included and the background hydrolysis rate of 4-NPA did not exceed 6\% of the catalysed rate for any assay mixture tested. The uncatalysed hydrolysis rates were subtracted from the corresponding enzyme catalysed rates. In addition, to determine whether there was any influence of assay $\mathrm{pH}$ on esterase activities between WT and engineered enzymes, assays were measured by production of 4-nitrophenol measured at its isosbestic point $(348 \mathrm{~nm})$ and lambda max $(405 \mathrm{~nm})$ over the $\mathrm{pH}$ range $6.8-8$ with 4 -NPA $(0.5 \mathrm{mM})$ at $28^{\circ} \mathrm{C}$, and product formation was monitored over $10 \mathrm{~min}$.

Sodium nitrate inhibition of WT and designed carbonic anhydrases was examined over the concentration range $50-3,000 \mathrm{mM}$ at eight substrate 4 -NPA concentrations between 90 and 2,000 $\mathrm{mM}$. The inhibitor concentration required to reduce activity by $50 \%$ (IC50) was determined for each of the enzymes at each substrate concentration.
To determine the effect of urea on 4-NPA activity of bCAII and engineered enzymes, the denaturant was added to assay mixtures at a final concentration of between 500 and $4,000 \mathrm{mM}$ with a final substrate concentration of $1 \mathrm{mM}$ and otherwise conducted under the standard assay conditions described above. Similarly, the effect of $\mathrm{Na}_{2} \mathrm{SO}_{4}$ over the range $250-1,850 \mathrm{mM}$, NaCl between $750-3,000 \mathrm{mM}$ and $\mathrm{GuHCl}$ between $250-3,000 \mathrm{mM}$ were assessed by enzyme assay.

In silico modelling and calculations. MD simulations were carried out on using the WT and M4 crystal structures as starting geometries to investigate the differences in salt-protein interactions and to attempt to rationalize the differences in thermostability under different salinity conditions. Simulations were performed using AMBER14 (ref. 35) and employed the ff99SB-ildn ${ }^{*}$ force field ${ }^{36,37}$ for non-coordinating protein residues and the zinc AMBER force field ${ }^{38}$ for the $\mathrm{Zn}^{2+}$ coordination environment, which included a coordinated hydroxide group. $\mathrm{Na}^{+}$ and $\mathrm{Cl}^{-}$parameters were taken from Joung and Cheatham ${ }^{39}$. The $\mathrm{NO}_{3}^{-}$and $\mathrm{HSO}_{4}^{-}$structures were optimized using $\mathrm{DMol} 3$ with all fine-grained defaults as implemented in Accelrys Materials Studio 7.0 (ref. 40) employing the PBE functional ${ }^{41}$ and the DNP basis set (double numerical quality with polarization functions comparable to the $6-31 \mathrm{G}^{* *}$ basis set). The anions were parameterized for MD employing BCC charges using the antechamber code as implemented in AmberTools15 (ref. 35) and treated with the General AMBER force field for simulation. For the $\mathrm{NaCl}$ simulations, the WT and M4 structures were neutralized and had further $\mathrm{Na}+$ and $\mathrm{Cl}$ - ions added (using the addions 2 command in $\mathrm{xLEaP}$ ) to provide a final count of 130 additional $\mathrm{NaCl}$. For the $\mathrm{NaNO}_{3}$ or $\mathrm{NaHSO}_{4}$ simulations, the WT and M4 enzymes were first neutralized with $\mathrm{Na}^{+}$cations, after which single units of $\mathrm{NaNO}_{3}$ or $\mathrm{NaHSO}_{4}$ were created and then added in excess to the systems using the solvate shell command xLEaP. The ions were then pared back to provide $130 \mathrm{NaNO}_{3}$ or $\mathrm{NaHSO}_{4}$ above the neutralizing $\mathrm{Na}^{+}$cations using an in-house python script. All systems were finally solvated in octahedral TIP3P water boxes, the sizes of which were adjusted to provide approximately equal total concentrations for the systems (final system parameters are provided in Supplementary Table 3). Although not expected to be the dominant species at our experimental $\mathrm{pH}$ levels, $\mathrm{NaHSO}_{4}$ was used instead of $\mathrm{Na}_{2} \mathrm{SO}_{4}$ due to the latter forming structured clusters in early simulations. All simulations were performed at constant pressure using the Berendsen barostat with isotropic position scaling $(\mathrm{NTP}=1)$ and a pressure relaxation time of $2 \mathrm{ps}$. The Langevin thermostat was used for temperature regulation. Long range electrostatic interactions were treated with the particle mesh Ewald method beyond $12 \AA$. Each system was minimized to relax high-energy contacts while restraining the protein backbone. Simulations were carried out at $298 \mathrm{~K}$ for $600 \mathrm{~ns}$ employing a $2 \mathrm{fs}$ timestep with SHAKE constraints and a non-bonded distance cutoff of $12.0 \AA$. Coordinates were saved at $10 \mathrm{ps}$ intervals to give final trajectories consisting of 60,000 frames. Inspection of the RMSD plots for the protein backbone atoms and the radius of gyration for each system indicated that the simulations had typically stabilized by $50-100 \mathrm{~ns}$, hence the first $100 \mathrm{~ns}$ was discarded and all analysis was carried out on the final $500 \mathrm{~ns}$. Enzyme images were produced and physical parameters were calculated using either Discovery Studio 3.5 (ref. 42 ), VMD $^{43}$ or cpptraj within AmberTools15.

\section{References}

1. Zaccai, G. \& Eisenberg, H. Halophilic proteins and the influence of solvent on protein stabilization. Trends Biochem. Sci. 15, 333-337 (1990).

2. Madern, D., Ebel, C. \& Zaccai, G. Halophilic adaptation of enzymes. Extremophiles 4, 91-98 (2000).

3. Mevarech, M., Frolow, F. \& Gloss, L. M. Halophilic enzymes: proteins with a grain of salt. Biophys. Chem. 86, 155-164 (2000).

4. Siglioccolo, A., Paiardini, A., Piscitelli, M. \& Pascarella, S. Structural adaptation of extreme halophilic proteins through decrease of conserved hydrophobic contact surface. BMC Struct. Biol. 11, 50 (2011).

5. Paul, S., Bag, S. K., Das, S., Harvill, E. T. \& Dutta, C. Molecular signature of hypersaline adaptation: insights from genome and proteome composition of halophilic prokaryotes. Genome Biol. 9, R70 (2008).

6. Premkumar, L. et al. Three-dimensional structure of a halotolerant algal carbonic anhydrase predicts halotolerance of a mammalian homolog. Proc. Natl Acad. Sci. USA 102, 7493-7498 (2005).

7. De Regil, R. \& Sandoval, G. Biocatalysis for biobased chemicals. Biomolecules $\mathbf{3}$, 812-847 (2013).

8. Robles-Medina, A., González-Moreno, P. A., Esteban-Cerdán, L. \& Molina-Grima, E. Biocatalysis: towards ever greener biodiesel production. Biotechnol. Adv. 27, 398-408 (2009).

9. Kanth, B. K., Lee, J. \& Pack, S. P. Carbonic anhydrase: its biocatalytic mechanisms and functional properties for efficient $\mathrm{CO}_{2}$ capture process development. Eng. Life Sci. 13, 422-431 (2013).

10. Sharma, V. \& Kundu, P. P. Biocatalysts in microbial fuel cells. Enzyme Microb. Technol. 47, 179-188 (2010).

11. Bornscheuer, U. T. et al. Engineering the third wave of biocatalysis. Nature 485, 185-194 (2012).

12. Munawar, N. \& Engel, P. C. Prospects for robust biocatalysis: engineering of novel specificity in a halophilic amino acid dehydrogenase. Extremophiles 17, 43-51 (2013). 
13. Tokunaga, H., Arakawa, T. \& Tokunaga, M. Engineering of halophilic enzymes: two acidic amino acid residues at the carboxy-terminal region confer halophilic characteristics to Halomonas and Pseudomonas nucleoside diphosphate kinases. Protein Sci. 17, 1603-1610 (2008).

14. Tadeo, X. et al. Structural basis for the aminoacid composition of proteins from halophilic archea. PLoS Biol. 7, e1000257 (2009).

15. Zheng, J., Avvaru, B. S., Tu, C., McKenna, R. \& Silverman, D. N. Role of hydrophilic residues in proton transfer during catalysis by human carbonic anhydrase II. Biochemistry 47, 12028-12036 (2008).

16. Innocenti, A., Vullo, D., Scozzafava, A. \& Suparan, C. T. Carbonic anhydrase inhibitors. Inhibition of isozymes I, II, IV, V, and IX with anions isosteric and isoelectronic with sulfate, nitrate, and carbonate. Bioorg. Med. Chem. Lett. 15, 567-571 (2005).

17. Hough, D. W. \& Danson, M. J. Extremozymes. Curr. Opin. Chem. Biol. 3, 39-46 (1999).

18. Bageshwar, U. K. et al. Natural protein engineering: a uniquely salt-tolerant, but not halophilic, alpha-type carbonic anhydrase from algae proliferating in low- to hyper-saline environments. Protein Eng. Des. Sel. 17, 191-200 (2004).

19. Lawrence, M. S., Phillips, K. J. \& Liu, D. S. Supercharging proteins can impart unusual resilience. J. Am. Chem. Soc. 129, 10110-10112 (2007).

20. Talon, R., Coquelle, N., Madern, D. \& Girard, E. An experimental point of view on hydration/solvation in halophilic proteins. Front. Microbiol 21, 66 (2014).

21. Elcock, A. H. \& McCammon, J. A. Electrostatic contributions to the stability of halophilic proteins. J. Mol. Biol. 280, 731-748 (1998).

22. Tokuriki, N. \& Tawfik, D. S. Protein dynamism and evolvability. Science 324, 203-207 (2009).

23. Steiner, H. \& Linskog, S. Effects of high concentrations of salt on the esterase activity of human carbonic anhydrase. FEBS Lett. 24, 85-88 (1972).

24. Innocenti, A., Zimmermann, S., Ferry, J. G., Scozzafava, A. \& Supuran, C. T. Carbonic anhydrase inhibitors. Inhibition of the zinc and cobalt $\gamma$-class enzyme from the archaeon Methanosarcina thermophila with anions. Bioorg. Med. Chem. Lett. 14, 3327-3331 (2004).

25. Bhuyan, A. K. On the mechanism of SDS-induced protein denaturation. Biopolymers 93, 186-199 (2010).

26. Kabsch, W. XDS. Acta Crystallogr. D Biol. Crystallogr. 66, 125-132 (2010).

27. Winn, M. D. et al. Overview of the CCP4 suite and current developments. Acta Crystallogr. D Biol. Crystallogr. 67, 235-242 (2011).

28. McCoy, A. J. et al. Phaser crystallographic software. J. Appl. Crystallogr. 40, 658-674 (2007).

29. Murshudov, G. N. et al. REFMAC5 for the refinement of macromolecular crystal structures. Acta Crystallogr. D Biol. Crystallogr. 67, 355-367 (2011).

30. Emsley, P., Lohkamp, B., Scott, W. G. \& Cowtan, K. Features and development of Coot. Acta Crystallogr. D Biol. Crystallogr. 66, 486-501 (2010).

31. Seabrook, S. A. \& Newman, J. High-throughput thermal scanning for protein stability: making a good technique more robust. ACS Comb. Sci. 15, 387-392 (2013).

32. He, F., Hogan, S., Latypov, R. F., Narhi, L. O. \& Razinkov, V. I. High throughput thermostability screening of monoclonal antibody formulations. J. Pharm. Sci. 99, 1707-1720 (2010).

33. Louis-Jeune, C., Andrade-Navarro, M. A. \& Perez-Iratxeta, C. Prediction of protein secondary structure from circular dichroism using theoretically derived spectra. Proteins 80, 374-381 (2012).

34. Pocker, Y. \& Stone, J. T. The catalytic versatility of erythrocyte carbonic anhydrase. The enzyme-catalyzed hydrolysis of $p$-nitrophenyl acetate. J. Am. Chem. Soc. 87, 5497-5498 (1965).

35. Case, D. A. et al. AMBER 2015 (University of California, 2015).

36. Best, R. B. \& Hummer, G. Optimized molecular dynamics force fields applied to the helix-coil transition of polypeptides. J. Phys. Chem. B 113, 9004-9015 (2009).
37. Lindorf-Larsen, K. et al. Improved side-chain torsion potentials for the Amber ff99SB force field. Proteins 78, 1950-1958 (2010).

38. Peters, M. B. et al. Structural survey of zinc-containing proteins and development of the zinc AMBER force field (ZAFF). J. Chem. Theory Comput. 6, 2935-2947 (2010).

39. Joung, I. S. \& Cheatham, T. E. Determination of alkali and halide monovalent ion parameters for use in explicitly solvated biomolecular simulations. J. Phys. Chem. B. 112, 9020-9041 (2008).

40. Materials Studio v7.0, 2013, Accelrys Software Inc.

41. Perdew, J. P., Burke, K. \& Ernzerhof, M. Generalized gradient approximation made simple. Phys. Rev. Lett. 77, 3865 (1996).

42. Accelrys Discovery Studio: Accelrys Software Inc. Discovery Studio Modeling Environment, Release 3.5. (2012).

43. Humphrey, W., Dalke, A. \& Schulten, K. VMD: visual molecular dynamics. J. Mol. Graph. 14, 33-38 (1996).

44. Phan, D. T. et al. A study of bovine and human carbonic anhydrases as a model enzyme system for $\mathrm{CO}_{2}$ hydration in post combustion capture. Int. J. Greenh. Gas Control 37, 85-89 (2015).

\section{Acknowledgements}

We thank the Australian Synchrotron and beamline scientists for access to the MX1 beamline, and thank Peter Campbell and Chunhong Chen, CSIRO, for protein analysis and initial cloning experiments, respectively. All crystals were grown in the Collaborative Crystallisation Centre (C3) at CSIRO. We also acknowledge the staff and facilities of CSIRO Advanced Scientific Computing for provision of computational resources. The financial support of the Australian National Low Emissions Coal Alternatives R\&D fund and CSIRO is acknowledged.

\section{Author contributions}

A.C.W. and V.S.H. conceived the idea and A.C.W. developed the rational design strategy and performed the molecular dynamics calculations. M.W. and G.D. performed the molecular biology and biochemical assays and SAS undertook thermal unfolding experiments. J.N. and T.S.P. performed the X-ray crystallography and solved the structures. V.S.H. and A.C.W. analysed the data and prepared the manuscript.

\section{Additional information}

Accession codes: Coordinates and structure factors for M1, M2, M3 and M4 have been deposited in the RCSB Protein Data Bank under accession codes 4CNR, 4CNV, 4CNW and $4 \mathrm{CNX}$, respectively.

Supplementary Information accompanies this paper at http://www.nature.com/ naturecommunications

Competing financial interests: The authors declare no competing financial interests.

Reprints and permission information is available online at http://npg.nature.com/ reprintsandpermissions/

How to cite this article: Warden, A. C. et al. Rational engineering of a mesohalophilic carbonic anhydrase to an extreme halotolerant biocatalyst. Nat. Commun. 6:10278 doi: 10.1038/ncomms10278 (2015).

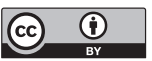

This work is licensed under a Creative Commons Attribution 4.0 International License. The images or other third party material in this article are included in the article's Creative Commons license, unless indicated otherwise in the credit line; if the material is not included under the Creative Commons license, users will need to obtain permission from the license holder to reproduce the material To view a copy of this license, visit http://creativecommons.org/licenses/by/4.0/ 